\title{
Ethnic specific recommendations in clinical practice guidelines: a first exploratory comparison between guidelines from the USA, Canada, the UK, and the Netherlands
}

\author{
D R Manna, M A Bruijnzeels, H G A Mokkink, M Berg
}

See end of article for authors' affiliations

\section{Correspondence to:}

D R Manna, PO Box 1738, 3000 DR Rotterdam, The Netherlands;

Manna@bmg.eur.nl

Accepted for publication 19 January 2003
Objectives: To investigate whether clinical practice guidelines in different countries take ethnic differences between patients into consideration and to assess the scientific foundation of such ethnic specific recommendations.

Design: Analysis of the primary care sections of clinical practice guidelines.

Setting: Primary care practice guidelines for type 2 diabetes mellitus, hypertension, and asthma developed in the USA, Canada, the UK, and the Netherlands.

Main outcome measures: Enumeration of the ethnic specific information and recommendations in the guidelines, and the scientific basis and strength of this evidence.

Results: Different guidelines do address ethnic differences between patients, but to a varying extent. The USA guidelines contained the most ethnic specific statements and the Dutch guidelines the least. Most ethnic specific statements were backed by scientific evidence, usually arising from descriptive studies or narrative reviews.

Conclusion: The attention given to ethnic differences between patients in clinical guidelines varies between countries. Guideline developers should be aware of the potential problems of ignoring differences in ethnicity.
O ver the past 20 years clinical practice guidelines have become an increasingly popular tool for implementation of scientifically based clinical information to improve the quality of health care. Many countries have produced such guidelines, mainly via specialist and/or general practice organisations. As defined by the Institute of Medicine (USA), clinical practice guidelines are "systematically developed statements to assist practitioner and patient decisions about appropriate health care for specific clinical circumstances". ${ }^{1}$ These statements should be based on the best available scientific evidence and practical knowledge; however, the increasing number of clinical guidelines has stimulated discussion about their value. ${ }^{2-6}$

An area that has received less attention in such discussions is the "specific clinical circumstances". Besides the disease specific characteristics, the "specific clinical circumstances" usually refer to the age and sex of the patient. However, with the increase in migration to western countries during the last 50 years, these western countries have increasingly become more multicultural and physicians are increasingly confronted with patients from diverse ethnic groups. In some of these groups particular diseases can be more prevalent or more severe, and this may also determine the patient's clinical circumstance. $^{7-10}$ Ignorance of ethnic differences between patients could lead to inferior quality of care for ethnic minorities. Many potentially avoidable procedures such as amputations, avoidable hospital admissions and readmissions, avoidable pain from cancer, untreated disease, and deaths are associated with a lower quality of care for ethnic minorities. ${ }^{11}{ }^{12}$ The question as to whether ethnicity should be a specific clinical circumstance systematically taken into consideration in clinical practice guidelines has not yet been fully addressed. The aim of the present study was to investigate whether clinical practice guidelines in different countries take ethnic differences between patients into consideration, and the scientific basis and strength of such ethnic specific recommendations.

\section{METHODS}

The clinical guidelines for three prevalent and chronic health problems-type 2 diabetes mellitus, hypertension, and asthma-used in four western countries were examined between 2000 and July 2001. These particular health problems were selected because of the relatively high impact of these diseases in western countries and because of the expected differences between members of different ethnic groups. For these three health problems primary care guidelines from national organisations in the USA, Canada, the UK, and the Netherlands were analysed $(n=13$; one guideline per disease from each country except the Dutch asthma guidelines which consisted of two separate guidelines, one for diagnostics and one for treatment). The USA guidelines were developed by the National Heart, Lung and Blood Institute (asthma 1997; hypertension 1997) and the American Diabetes Association (2001), ${ }^{13-15}$ the Canadian guidelines by the Canadian Medical Association (asthma 1999; hypertension 1999; diabetes 1998), ${ }^{16-18}$ the British guidelines by the British Thoracic Society (1997), the British Hypertension Society (1999), and Diabetes UK (2000), ${ }^{19-21}$ and the guidelines used by Dutch general practitioners (GPs) were developed by the Dutch College of General Practitioners (asthma 2001; hypertension 1997; diabetes 1999). ${ }^{22-25}$ Because some guidelines covered the whole spectrum of care and others focused on primary care only, we studied only the primary care sections of the different guidelines.

Each guideline was carefully examined (by DRM) and any ethnic specific statement and/or recommendation made was marked and noted. This procedure was repeated (by MAB) and an inter-rater agreement was calculated. Consensus was 
Box 1 Categories of strength of evidence of statements in clinical guidelines (developed by the North of England evidence-based guideline development project)

la: Evidence from meta-analysis of randomised controlled trials

lb: Evidence from at least one randomised controlled trial lla: Evidence from at least one controlled study without randomisation

llb: Evidence from at least one other type of quasiexperimental study

III: Evidence from descriptive studies, such as comparative studies, correlation studies and case controlled studies

IV: Evidence from expert committee reports or opinions or clinical experience of respected authorities, or both

IV*: Narrative reviews

* Narrative reviews could not be properly categorised into the categories of the North of England evidence-based guideline development project. For this reason we added $\mathrm{IV}^{*}$ to the existing categories.

reached in all cases of disagreement. The identified statements were then organised into the following coherent themes:

- epidemiology (including aetiology);

- diagnostics (including screening);

- treatment (including therapy);

- patient education;

- (content of) medical record;

- (overall) cultural sensitivity.

The statements were designated either as merely empirical information/facts or as specific recommendations in the guidelines. The underlying scientific evidence for each ethnic specific statement was collected by checking all the references mentioned in the guideline for the specific statements; by reading the evidence, the strength of the evidence was then graded according to an adjusted version of the schemes of the North of England guideline development project (box 1). ${ }^{26}$

\section{RESULTS}

The overall inter-rater agreement was good. Forty seven segments of text regarding ethnic differences were identified in the guidelines, of which 42 were identified by both authors (inter-rater agreement: 89\%). All 47 were included in the analysis.

\section{Ethnic specific information in diabetes guidelines}

Table 1 gives the analysis of the diabetes guidelines. All four guidelines made an empirical statement about a higher prevalence of diabetes among certain ethnic groups. The US, Canadian and, to a lesser extent, the UK and Dutch guidelines had some additional statements (related mainly to diagnostics/ screening) about the consequences of this higher prevalence. The statements in the Canadian guideline were presented in a separate section dedicated to diabetes among their aboriginal population, except the recommendation to obtain insight into the ethnic and cultural influences on the nutrition of the patient.

\section{Scientific basis of ethnic specific information in diabetes guidelines}

For diabetes the different guidelines used different sources of evidence (research papers) for their ethnic specific statements. The evidence was mainly type III (descriptive) prevalence studies and all addressed their own national situation.
Ethnic specific information in hypertension guidelines

Table 2 presents the analysis of the hypertension guidelines. The Dutch guideline contained no ethnic specific statements, the Canadians had only one such statement (albeit an important one), and the US and UK reported more extensively (in separate paragraphs) about ethnic differences. The guidelines made empirical statements about (1) a higher prevalence, more severe hypertension, and a higher risk of complications in certain ethnic groups; (2) the difference in response to pharmacological treatment; and (3) the higher sensitivity to dietary salt restriction among black subjects. These empirical statements led to different treatment recommendations in the respective guidelines.

\section{Scientific basis of ethnic specific information in hypertension guidelines}

For epidemiology the evidence was primarily from type III (descriptive) studies or narrative reviews, while the evidence for the differential response to pharmacological treatment was mainly from randomised controlled trials. One study (type Ib) was used as evidence in both the US and UK guidelines.

\section{Ethnic specific information in asthma guidelines}

In the asthma guidelines (table 3 ) one empirical statement about the ethnic variability of lung function was found in both the US guideline (in a separate paragraph) and in the Dutch guideline. The US guideline also stressed the importance of a culture sensitive approach to the patient. The Canadian guideline made no ethnic specific statements, and the UK guideline had only one minor remark about the failure of attending education programmes.

\section{Scientific basis of ethnic specific information in asthma} guidelines

Almost all evidence in the guidelines for asthma were based on type III (descriptive) studies.

\section{DISCUSSION}

The results of this study show that clinical guidelines from the four western countries do contain ethnic specific information and recommendations, but to a varying extent. The Dutch guidelines contained only a few empirical facts and only once made an additional specific recommendation based on these facts. The other three guidelines added more recommendations to the empirical facts, only for hypertension in the case of the UK, only for diabetes in the case of Canada, but for all three health problems in US guidelines. The US guidelines therefore gave the most attention to ethnic differences by presenting empirical facts as well as formulating specific recommendations.

Because most of the statements about ethnic differences in the different guidelines were based on differences in epidemiology (prevalences), the scientific evidence used consisted mainly of descriptive studies or narrative reviews and addressed their national situation. The US guidelines tended to use more evidence.

This is a first exploratory study of the attention given in clinical practice guidelines to ethnic differences. We focused on guidelines from only four western countries and thereby narrowed our scope considerably. Although our comparison is useful, it would be interesting to broaden it in further research by including guidelines from other countries with a relatively large group of subjects from ethnic minorities.

It is difficult to give an explanation for the difference in focus on ethnic differences in the guidelines found in this study because the guidelines are produced and used in the complex environment of a healthcare system. Ethical, economic, legal, political, and cultural aspects are involved which vary in the different countries. Because of historical developments, countries may have their own specific way of 
Table 1 Guidelines on diabetes mellitus type 2: comparison between countries on ethnic specific statements ${ }^{27-40}$

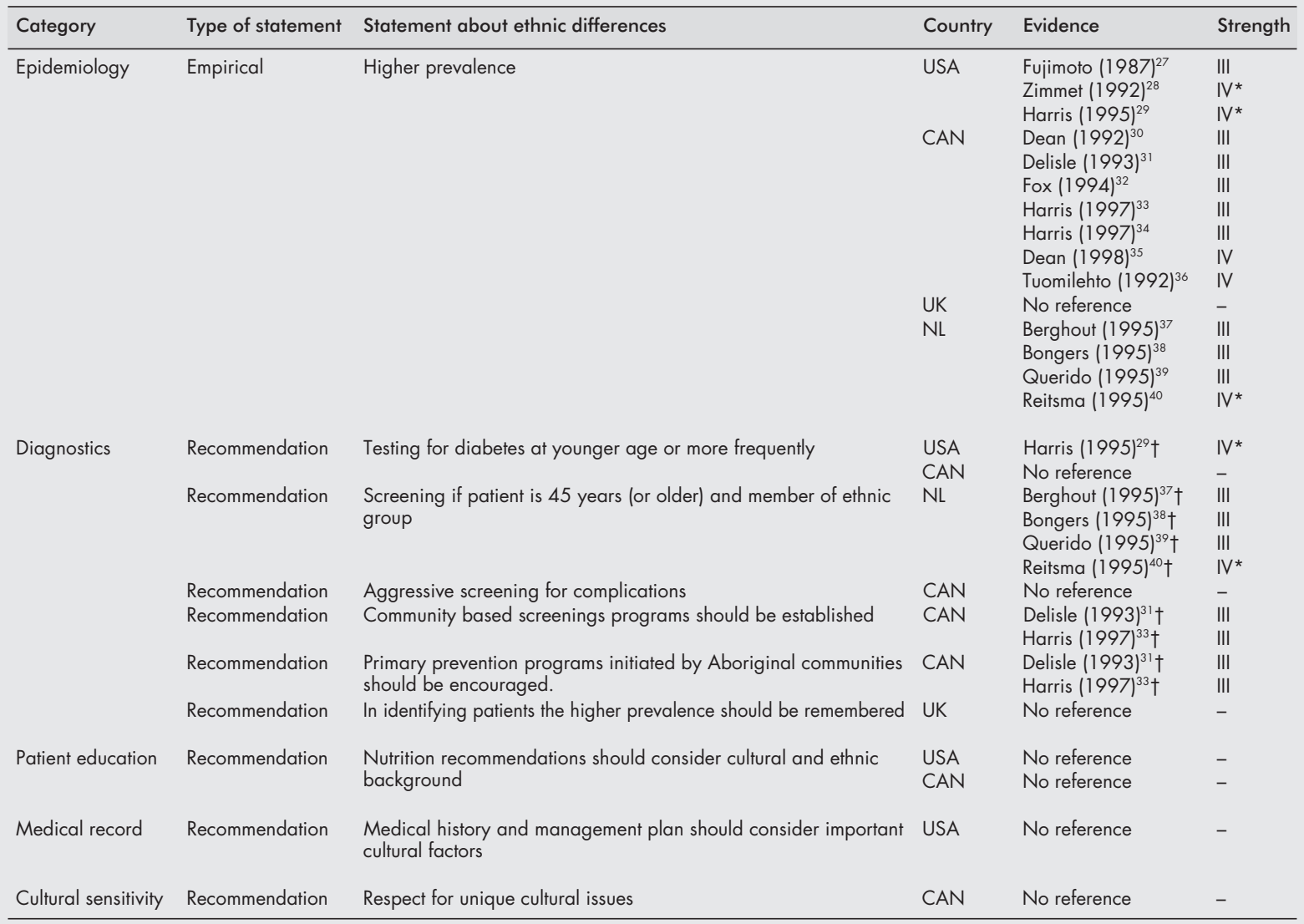

*Narrative reviews.

†There was no reference mentioned for this particular statement in the guideline, but because this statement is based on information about risk factors (high prevalences), it is probably based on the evidence about a higher prevalence in certain ethnic groups.

approaching ethnic differences. The USA and Canada, for example, have a long history of being multicultural societies with relatively large groups of native inhabitants and other subgroups. In the UK and the Netherlands, however, ethnic minorities are a more recent phenomenon resulting from labour and colonial migrants. These differences in historical background have led to political and cultural differences in facing questions concerning minority groups. Whereas the USA places both cultural and political emphasis on differences in ethnic identities, other countries do this to a lesser extent, resulting in other normative values. All these aspects could impact on the process of guideline development-for example, on the composition of the panel developing the guidelines which, in turn, could influence the process of decision making in the selection of relevant evidence and in the content of the guidelines. ${ }^{66-80}$ Although guidelines are considered to be products of evidence-based medicine and therefore primarily based on available scientific evidence, they always contain (either explicit or implicit) normative values of (individual) panel members.

Another factor to consider is the possibility that, because mainly local/national evidence was used to develop the ethnic specific recommendations, panel members in one country may consider that data are only applicable to ethnic groups in the country where the research was conducted. But do Afro-Americans in the USA differ from black subjects in the Netherlands and the UK; and do South Asians living in the USA differ from those in the UK, Canada or the Netherlands? As far as the medical differences discussed in this paper are concerned, the answer is probably not, because it is often reported that the higher prevalence and severity of diabetes and hypertension in certain ethnic groups and the differences in response to drugs result, at least in part, from genetic differences and the migration process. ${ }^{82} 83$

The above considerations raise interesting questions as to whether cultural differences between countries can explain different normative values between groups of guideline developers resulting in more or less ethnic specific recommendations in the guidelines, and whether health information about certain minority ethnic groups is applicable to similar groups in other countries. Since disease or health specific data on white subjects are accepted worldwide, it is legitimate to question why this does not apply to scientific data on differences between other ethnic groups. Future research should try to find the answers to these questions.

The development of guidelines is a complicated process in which many heterogeneous considerations are weighed against each other. Guidelines must be feasible and as clear, understandable and unambiguous as possible, given current healthcare practices. There will always be some reluctance about changes in current practice, and in describing exceptions and, for example, ethnic differences. Nevertheless, ethnic differences are present in all western societies and this issue can expect a higher priority in future research and health care. However, at present, the proportion of ethnic minorities in deprived neighbourhoods in the UK and the Netherlands is very large and, for the care in those underprivileged areas, ethnic specific recommendations in guidelines can already help practitioners in their daily practice and therefore should be implemented as soon as possible. If clinical recommendations do not accept the existence of clinically relevant ethnic differences in, for example, prevalence/complications and 
Table 2 Guidelines on hypertension: comparison between countries on ethnic specific statements ${ }^{81-58}$

\begin{tabular}{|c|c|c|c|c|c|}
\hline Category & Type of statement & Statement about ethnic differences & Country & Evidence & Strength \\
\hline Epidemiology & Empirical & Higher prevalence, more severe and higher risk for complications & USA & $\begin{array}{l}\text { Klag }(1997)^{41} \\
\text { Burt }(1995)^{42} \\
\text { Fang }(1996)^{43} \\
\text { Singh }(1996)^{44} \\
\text { Havas }(1996)^{45} \\
\text { Hall }(1997)^{46} \\
\text { Balarajan }(1991)^{56} \\
\text { McKeigue }(1991)^{57} \\
\text { Cappuccio }(1997)^{8} \\
\text { Williams }(1995)^{58}\end{array}$ & $\begin{array}{l}\text { IIb } \\
\text { III } \\
\text { III } \\
\text { III } \\
I^{*} \\
I^{*} \\
\text { III } \\
\text { III } \\
\text { III } \\
\text { IV }\end{array}$ \\
\hline \multirow[t]{9}{*}{ Treatment } & Empirical & Difference in response to pharmacological treatment & USA & $\begin{array}{l}\text { Townsend }(1990)^{47} \\
\text { SOLVD }(1991)^{48} \\
\text { Materson }(1993)^{49} \\
\text { Chen }(1993)^{50} \\
\text { Chen }(1995)^{51} \\
\text { Materson }(1993)^{49}\end{array}$ & $\begin{array}{l}\mathrm{lb} \\
\mathrm{lb} \\
\mathrm{lb} \\
\mathrm{lla} \\
\mathrm{lla} \\
\mathrm{lb}\end{array}$ \\
\hline & Empirical & Hypertension is sensitive to dietary salt restriction in black subjects & USA & $\begin{array}{l}\text { Weinberger }(1996)^{52} \\
\text { No reference }\end{array}$ & $I_{-}^{10}$ \\
\hline & Empirical & Lifestyle modifications are particularly important & USA & No reference & _- \\
\hline & Recommendation & $\begin{array}{l}\text { Black subjects require multi-drug therapy because of more severe } \\
\text { hypertension }\end{array}$ & USA & $\begin{array}{l}\text { Burt }(1995)^{42} \dagger \\
\text { Hall }(1997)^{46} \dagger\end{array}$ & $\begin{array}{l}\text { III } \\
\text { IV* }\end{array}$ \\
\hline & Recommendation & Achieve goal blood pressure of below $140 / 90 \mathrm{~mm} \mathrm{Hg}$ & USA & $\begin{array}{l}\text { Burt }(1995)^{42} \dagger \\
\text { Hall }(1997)^{46} \dagger\end{array}$ & $\begin{array}{l}\text { III } \\
\text { IV* }\end{array}$ \\
\hline & Recommendation & Emphasis on glucose tolerance, lipids and increased coronary risk & UK & $\begin{array}{l}\text { McKeigue }(1991)^{57} \\
\text { Williams }(1995)^{58}\end{array}$ & III \\
\hline & Recommendation & $\begin{array}{l}\text { Good blood pressure control important in South Asians with } \\
\text { diabetes }\end{array}$ & UK & No reference & - \\
\hline & Recommendation & $\begin{array}{l}\text { Aspirin and/or statin treatment may be indicated for South Asians } \\
\text { at high risk of CHD }\end{array}$ & UK & No reference & - \\
\hline & Recommendation & The start of drug therapy should be influenced by black race & CAN & No reference & - \\
\hline \multirow[t]{2}{*}{ Patient education } & Empirical & Requirement of more focused education & USA & $\begin{array}{l}\text { Enas }(1996)^{53} \\
\text { Howard }(1996)^{54} \\
\text { Winkleby }(1996)^{55} \\
\text { Havas }(1996)^{45}\end{array}$ & $\begin{array}{l}\text { III } \\
\text { III } \\
\text { III } \\
I^{*}\end{array}$ \\
\hline & Recommendation & $\begin{array}{l}\text { Advice to reduce fat and refined sugar intake and to increase } \\
\text { exercise }\end{array}$ & UK & No reference & - \\
\hline
\end{tabular}

* Narrative reviews.

†There was no reference mentioned for this particular statement in the guideline, but because this statement is based on information about risk factors (high prevalences), it is probably based on the evidence about a higher prevalence in certain ethnic groups.

response to pharmacological treatment, suboptimal or even harmful practices may occur. ${ }^{84}$ This also applies to the need for ethnic specific education and counselling and sensitivity towards differences in cultural values and norms, particularly when a positive clinical effect has been proved. By disregard- ing scientific evidence, the guideline may provide inaccurate information and thereby compromise the quality of care ${ }^{84}$; and by disregarding scientific evidence, the higher morbidity and mortality and the higher risk of complications with hypertension and diabetes will continue or even get worse because,

Table 3 Guidelines on asthma: comparison between countries on ethnic specific statements ${ }^{59-75}$

\begin{tabular}{|c|c|c|c|c|c|}
\hline Category & Type of statement & Statement about ethnic differences & Country & Evidence & Strength \\
\hline Epidemiology & Empirical & Hospitalisation and death rates highest among black subjects & USA & $\operatorname{CDC}(1996)^{59}$ & III \\
\hline \multirow[t]{9}{*}{ Diagnostics } & Empirical & Lung function varies across ethnic groups & USA & Woolcock $(1972)^{60}$ & III \\
\hline & & & & Hsu $(1979)^{61}$ & III \\
\hline & & & & Wall $(1982)^{62}$ & III \\
\hline & & & & Coultas $(1988)^{63}$ & III \\
\hline & & & & Crapo $(1988)^{64}$ & III \\
\hline & & & & Marcus $(1988)^{65}$ & III \\
\hline & & & & Coultas $(1994)^{66}$ & $\mathrm{IV}^{*}$ \\
\hline & & & NL & Quanjer $(1983)^{74}$ & IV* \\
\hline & & & & Quanjer $(1993)^{75}$ & $\mathrm{IV}^{*}$ \\
\hline \multirow[t]{7}{*}{ Patient education } & Empirical & $\begin{array}{l}\text { Failure of attending education programs is associated with } \\
\text { minority ethnic group }\end{array}$ & UK & Fitzgerald $(1994)^{73}$ & IV \\
\hline & Recommendation & Asthma education in native language and sensitive to patient's & USA & Manson $(1988)^{67}$ & III \\
\hline & & culture & & Pachter $(1993)^{68}$ & III \\
\hline & & & & Pachter $(1995)^{69}$ & III \\
\hline & & & & Risser $(1995)^{70}$ & III \\
\hline & & & & Kleinman $(1978)^{71}$ & IV \\
\hline & & & & Woloshin $(1995)^{72}$ & IV \\
\hline Medical record & Recommendation & Sociocultural beliefs should be an item in medical history & USA & No reference & - \\
\hline
\end{tabular}

*Narrative reviews. 


\section{Key messages}

- Guidelines from different countries differ in the attention given to ethnic differences between patients.

- Guidelines developed in the USA give the most attention to ethnic differences between patients compared with the UK, Canada and the Netherlands; Dutch guidelines give the least.

- Cultural differences between countries lead to differences in the content of guidelines.

- Although clinical practice guidelines are seen as products of evidence-based medicine, normative values also influence the content of guidelines.

- Disregarding scientific evidence about ethnic differences in guidelines could compromise the quality of care for ethnic minorities and could lead to unnecessary health problems in this group.

in the Netherlands, for example, members of the ethnic minority groups are relatively young and will therefore be faced with more morbidity in the future.

\section{CONCLUSIONS}

Differences in the attention given to ethnic differences between patients in clinical practice guidelines exist between countries. Whatever the explanations may be for these differences, guideline developers should be aware of the potential problems for patients from ethnic minority groups. Ethnic differences should play an important part in both screening the available evidence and in the development of the guideline-for example, the composition of the expert panel. With the increasing movement of people between countries, this aspect will become even more important in the future.

\section{Authors' affiliations}

D R Manna, M A Bruijnzeels, M Berg, Department of Health Policy \& Management, Erasmus MC, Rotterdam, The Netherlands H Mokkink, Centre for Quality of Care Research, UMC St. Radboud, University of Nijmegen, The Netherlands

\section{REFERENCES}

1 Field MJ, Lohr M. Clinical practice guidelines: directions for a new program. Washington, DC: National Academy Press, 1990.

2 Berg M. Problems and promises of the protocol. Soc Sci Med 1997:44:1081-8.

3 Cabana MD, Rand CS, Powe NR, et al. Why don't physicians follow clinical practice guidelines? A framework for improvement. JAMA 1999;282:1458-65.

4 Shaneyfelt TM, Mayo-Smith MF, Rothwangl J. Are guidelines following guidelines? The methodological quality of clinical practice guidelines in the peer-reviewed medical literature. JAMA 1999;281:1900-5

5 Grol R, Dalhuijsen J, Thomas S, et al. Attributes of clinical guidelines that influence use of guidelines in general practice: observational study. $B M$ 1998:317:858-61.

6 Woolf SH, Grol R, Hutchinson A, et al. Clinical guidelines: potential benefits, limitations, and harms of clinical guidelines. BM 1999;318:527-30

7 Kaplan NM. Ethnic aspects of hypertension. Lancet 1994;344:450-2.

8 Cappuccio FP, Cook DG, Atkinson RW, et al. Prevalence, detection, and management of cardiovascular risk factors in different ethnic groups in south London. Heart 1997;78:555-63.

9 Khattar RS, Swales JD, Senior R, et al. Racial variation in cardiovascular morbidity and mortality in essential hypertension. Heart 2000;83:267-71.

10 Partridge MR. In what way may race, ethnicity or culture influence asthma outcomes? Thorax 2000;55:175-6.

11 Freeman HP, Payne R. Racial injustice in health care. N Engl J Med 2000;342:1045-7.

12 Fiscella K, Franks P, Gold MR, et al. Inequality in quality. Addressing socioeconomic, racial, and ethnic disparities in health care. JAMA 2000;283:2579-84

13 National Asthma Education and Prevention Program. Guidelines for the diagnosis and management of asthma. Expert Panel Report 2. Report No. 97-4051. Bethesda, MD: National Institutes of Health, National Heart, Lung, and Blood Institute, 1997.
14 National High Blood Pressure Education Program. The sixth report of the Joint National Committee on prevention, detection, evaluation, and treatment of high blood pressure. Report No. 98-4080. Bethesda, MD National Institutes of Health. National Heart, Lung, and Blood Institute, 1997.

15 American Diabetes Association. Clinical practice recommendations 2001. Diabetes Care $2001 ; 24($ Suppl 1):S1-133.

16 Feldman RD, Campbell N, Larochelle P, et al. 1999 Canadian recommendations for the management of hypertension. Task Force for the Development of the 1999 Canadian Recommendations for the Management of Hypertension. Can Med Assoc J 1999;161/Suppl 12): S1-17.

17 Boulet LP, Becker A, Berube D, et al. Canadian asthma consensus report, 1999. Canadian Asthma Consensus Group. Can Med Assoc J 1999;161(11 Suppl):S1-61

18 Meltzer S, Leiter L, Daneman D, et al. 1998 clinical practice guidelines for the management of diabetes in Canada. Canadian Diabetes Association. Can Med Assoc J 1998;159(Suppl 8):S1-29.

19 British Thoracic Society. British guidelines on the management of asthma. Thorax 1997;52(Suppl 1):S1-21

20 Ramsay L, Williams B, Johnston G, et al. Guidelines for management of hypertension: report of the Third Working Party of the British Hypertension Society. J Hum Hypertens 1999:13:569-92.

21 Hall M, Tasker P, Lucas S. Recommendations for the management of diabetes in primary care. London: Diabetes UK, 2000.

22 Geijger RMM, Thiadens HA, Smeele IJM, et al. NHG-standaard COPD en Astma bij Volwassenen: Diagnostiek. Huisarts Wet 2001;44:107-17.

23 Geijger RMM, Van Hensbergen W, Bottema BJAM, et al. NHG-Standaard Astma bij Volwassenen: Behandeling. Huisarts Wet 2001:44:153-64.

24 Walma EP, Grundmeijer HGLM, Thomas S, et al. NHG-Standaard Hypertensie (eerste herziening). Huisarts Wet 1997;40:598-617.

25 Rutten GEHM, Verhoeven S, Heine R, et al. NHG-standaard Diabetes Mellitus type 2 (eerste herziening). Huisarts Wet 1999;42:67-84.

26 Eccles M, Freemantle N, Mason J. North of England evidence based guidelines development project: methods of developing guidelines for efficient drug use in primary care. BM 1998;316:1232-5.

27 Fujimoto WY, Leonetti DL, Kinyoun JL, et al. Prevalence of complications among second-generation Japanese-American men with diabetes, impaired glucose tolerance, or normal glucose tolerance. Diabetes 1987;36:730-9

28 Zimmet PZ. Kelly West Lecture 1991. Challenges in diabetes epidemiology - from West to the rest. Diabetes Care 1992;15:232-52.

29 Harris MI, Couric CC, Reiber G, et al. Diabetes in America. 2nd ed. $\mathrm{NIH}$ Publication No. 95-1468. Washington DC: US Government Printing Office, 1995

30 Dean HJ, Mundy RL, Moffatt M. Non-insulin-dependent diabetes mellitus in Indian children in Manitoba. Can Med Assoc J 1992;147:52-7.

31 Delisle HF, Ekoe JM. Prevalence of non-insulin-dependent diabetes mellitus and impaired glucose tolerance in two Algonquin communities in Quebec. Can Med Assoc J 1993;148:41-7.

32 Fox C, Harris SB, Whalen-Brough E. Diabetes among native Canadians in Northwestern Canada: 10 years later. Chronic Dis Can 1994; 15:92-6.

33 Harris SB, Gittelsohn J, Hanley A, et al. The prevalence of NIDDM and associated risk factors in native Canadians. Diabetes Care 1997:20:185-7.

34 Harris SB, Caulfield LE, Sugamori ME, et al. The epidemiology of diabetes in pregnant native Canadians. A risk profile. Diabetes Care 1997; 20: 1422-5

35 Dean H. NIDDM-Y in first nation children in Canada. Clin Pediatr (Phila) 1998;37:89-96.

36 Tuomilehto J, Knowler WC, Zimmet P. Primary prevention of non-insulin-dependent diabetes mellitus. Diabetes Metab Rev 1992:8:339-53.

37 Berghout A, Dijkstra S. Type II diabetes mellitus in Hindus; new manifestations of old disease pictures. Ned Tijdschr Geneeskd 1995;139:3-7.

38 Bongers I, Westendorp RGJ, Stolk B, et al. Early coronary heart disease together with type II diabetes mellitus in persons of Hindustani origin. Ned Tijdschr Geneeskd 1995;139:16-18.

39 Querido JD. Prevalence of type-2 diabetes mellitus in three inner city practices. Huisarts Wet 1995;38:250-4.

40 Reitsma JB. Mortaliteit en morbiditeit van hart: en vaatziekten bij vrouwen. Hart Bulletin 1995;25:5-10.

41 Klag MJ, Whelton PK, Randall BL, et al. End-stage renal disease in African-American and white men. 16-year MRFIT findings. JAMA 1997;277:1293-8.

42 Burt VL, Cutler JA, Higgins $M$, et al. Trends in the prevalence awareness, treatment, and control of hypertension in the adult US population. Data from the health examination surveys, 1960 to 1991. Hypertension 1995;26:60-9.

43 Fang J, Madhavan S, Alderman MH. The association between birthplace and mortality from cardiovascular causes among black and white residents of New York City. N Engl J Med 1996;335:1545-51.

44 Singh GK, Kochanek KD, MacDorman MF. Advance report of final mortality statistics. Mon Vital Stat Rep 1996;45(3, suppl): 1-76.

45 Havas S, Sherwin R. Putting it all together: summary of the NHLB Workshop of the Epidemiology of Hypertension in Hispanic American, Native American, and Asian/Pacific Islander American Populations. Public Health Rep 1996;111(Suppl 2):77-9.

46 Hall WD, Ferrario CM, Moore MA, et al. Hypertension-related morbidity and mortality in the southeastern United States. Am J Med Sci 1997;313:195-209. 
47 Townsend RR, DiPette DJ, Goodman R, et al. Combined alpha/beta-blockade versus beta 1 -selective blockade in essentia hypertension in black and white patients. Clin Pharmacol Ther 1990;48:665-75.

48 Anonymous. Effect of enalapril on survival in patients with reduced left ventricular ejection fractions and congestive heart failure. The SOLVD Investigators. N Engl J Med 1991;325:293-302.

49 Materson BJ, Reda DJ, Cushman WC, et al. Single-drug therapy for hypertension in men. A comparison of six antihypertensive agents with placebo. The Department of Veterans Affairs Cooperative Study Group on Antihypertensive Agents. N Engl J Med 19931;328:914-21.

50 Chen MF, Chen CC, Chen WJ, et al. Dose titration study of isradipine in Chinese patients with mild to moderate essential hypertension. Cardiovasc Drugs Ther 1993:7:133-8.

51 Chen MF, Yang CY, Chen WJ, et al. A double-blind comparison of once-daily metoprolol controlled-release and atenolol in the treatment of Chinese patients with mild to moderate hypertension. Cardiovasc Drugs Ther 1995;9:401-6.

52 Weinberger $M H$. Salt sensitivity of blood pressure in humans. Hypertension 1996;27:481-90.

53 Enas EA, Garg A, Davidson MA, et al. Coronary heart disease and its risk factors in first-generation immigrant Asian Indians to the United States of America. Indian Heart J 1996;48:343-53.

54 Howard BV, Lee ET, Yeh JL, et al. Hypertension in adult American Indians. The Strong Heart Study. Hypertension 1996;28:256-64.

55 Winkleby MA, Kraemer $\mathrm{H}$, Lin J, et al. Sociodemographic influences on Hispanic-white differences in blood pressure. Public Health Rep 1996;111(Suppl 2):30-2.

56 Balarajan R. Ethnic differences in mortality from ischaemic heart disease and cerebrovascular disease in England and Wales. BM 1991;302:560-4.

57 McKeigue PM, Shah B, Marmot MG. Relation of central obesity and insulin resistance with high diabetes prevalence and cardiovascular risk in South Asians. Lancet 1991;337:382-6.

58 Williams B. Westernised Asians and cardiovascular disease: nature or nurture? Lancet 1995;345:401-2.

59 Centers for Disease Control and Prevention. Asthma mortality and hospitalization among children and young adults - United States, 1990-1993. MMWR 1996;45:350-3.

60 Woolcock AJ, Colman MH, Blackburn CR. Factors affecting normal values for ventilatory lung function. Am Rev Respir Dis 1972;106:692-709.

61 Hsu KH, Jenkins DE, Hsi BP, et al. Ventilatory functions of normal children and young adults-Mexican American, white, and black. I. Spirometry. J Pediatr 1979:95: 14-23.

62 Wall MA, Olson D, Bonn BA, et al. Lung function in North American Indian children: reference standards for spirometry, maximal expiratory flow volume curves, and peak expiratory flow. Am Rev Respir Dis 1982;125:158-62.

63 Coultas DB, Howard CA, Skipper BJ, et al. Spirometric prediction equations for Hispanic children and adults in New Mexico. Am Rev Respir Dis 1988;138:1386-92.
64 Crapo RO, Lockey J, Aldrich V, et al. Normal spirometric values in healthy American Indians. J Occup Med 1988;30:556-60.

65 Marcus EB, MacLean CJ, Curb JD, et al. Reference values for FEV 1 in Japanese-American men from 45 to 68 years of age. Am Rev Respir Dis 1988; 138: 1393-7.

66 Coultas DB, Gong H Jr, Grad R, et al. Respiratory diseases in minorities of the United States. Am J Respir Crit Care Med 1994;149:S93-131.

67 Manson A. Language concordance as a determinant of patient compliance and emergency room use in patients with asthma. Med Care 1988;26: $1119-28$.

68 Pachter LM, Weller SC. Acculturation and compliance with medical therapy. J Dev Behav Pediatr 1993;14:163-8.

69 Pachter LM, Cloutier MM, Bernstein BA. Ethnomedical (folk) remedies for childhood asthma in a mainland Puerto Rican community. Arch Pediatr Adolesc Med 1995;149:982-8.

70 Risser AL, Mazur LJ. Use of folk remedies in a Hispanic population. Arch Pediatr Adolesc Med 1995;149:978-81.

71 Kleinman A, Eisenberg L, Good B. Culture, illness, and care: clinical lessons from anthropologic and cross-cultural research. Ann Intern Med 1978;88:251-8

72 Woloshin S, Bickell NA, Schwartz LM, et al. Language barriers in medicine in the United States. JAMA 1995;273:724-8.

73 FitzGerald JM. Psychosocial barriers to asthma education. Chest 1994:106(4 Suppl):260-3S

74 Quanjer PH. Standardized lung function testing. Report working party standardization of lung function tests, European Community for Coal and Steel. Bull Eur Physiopathol Respir 1983;19(Suppl 5):1-95.

75 Quanjer PH, Tammeling GJ, Cotes JE, et al. Lung volumes and forced ventilatory flows. Report Working Party Standardization of Lung Function Tests, European Community for Steel and Coal. Official Statement of the European Respiratory Society. Eur Respir J Suppl 1993;1 6:5-40.

76 Leape LL, Park RE, Kahan JP, et al. Group judgements of appropriateness: the effect of panel composition. Qual Assur Health Care 1992:4:151-9.

77 Naylor CD. Grey zones of clinical practice: some limits to evidence-based medicine. Lancet 1995;345:840-2.

78 Casparie AF. The ambiguous relationship between practice variation and appropriateness of care: an agenda for further research. Health Policy 1996; 35:247-65

79 Grimshaw J, Eccles M, Russell I. Developing clinically valid practice guidelines. J Eval Clin Pract 1995;1:37-48.

80 Berg M. Order(s) and disorder(s): of protocols and medical practices. In Mol MBA, ed. Differences in medicine. Unraveling practices, techniques and bodies. Durham: Duke University Press, 1998: 226-46.

81 Epstein S. Bodily differences and collective identities: representation, generalization, and the politics of gender and race in biomedical research in the United States. Body and Society 2003 (in press).

82 Wood AJ. Racial differences in the responses to drugs. Pointers to genetic differences. N Engl J Med 2001;344:1394-6.

83 Middelkoop BJC. Diabetes: a true problem. Thesis. Amsterdam: Vrije Universiteit Amsterdam, 2001

84 Shekelle PG, Woolf SH, Eccles M, et al. Clinical guidelines: developing guidelines. BM 1999;318:593-6. 